\title{
ARTIKELEN
}

\author{
THEMA-ARTIKEL
}

\section{Positieve bestuurskunde}

\section{Naar een robuust positief perspectief op de overheid ${ }^{*}$}

\author{
Scott Douglas, Trui Steen \& Zeger van der Wal
}

\begin{abstract}
Burgers en bestuurskundigen excelleren in het aanwijzen en analyseren van slecht bestuur. Het is ook belangrijk om overheidsfalen te begrijpen, maar terwijl het bestuur het in de Lage Landen het gemiddeld goed en internationaal gezien zelfs heel goed doet, gaat de meeste aandacht naar de fouten. Dit artikel pleit voor een bewust positief perspectief op de overheid in aanvulling op het bestaande onderzoek. Wetenschappelijk gezien moet de bestuurskunde zichzelf de ambitie stellen om de bestaande positieve inzichten beter met elkaar te verbinden en te aggregeren. Maatschappelijk gezien moet de discipline voorkomen dat de huidige negatieve teneur leidt tot een afwijzing van het democratische bestuur of de inzet van onbewezen wondermiddelen. Dit artikel werkt de beginselen voor een positieve bestuurskunde uit en introduceert de verdere bijdragen in dit themanummer, die gezamenlijk een eerste invulling geven aan een robuust positief perspectief op de overheid.
\end{abstract}

\section{De noodzaak voor positieve bestuurskunde}

Wanpresterend bestuur of overmatig kritische burgers?

Burgers excelleren in het aanwijzen van slecht bestuur. Hun onvrede over de overheid wordt zichtbaar in de demonstraties van 'gele hesjes', de opkomst van anti-systeempartijen, of andere 'boze burger bewegingen'. Het gaat hierbij niet alleen om incidentele uitbarstingen. Verschillende enquêtes, media-analyses en casusonderzoeken laten zien dat de publieke opinie negatief gekant is tegen de publieke sector; vooral ambtenaren moeten het bezuren en krijgen er regelmatig zelfs openlijk van politici van langs (zie bijvoorbeeld Van der Wal, 2016). Onderzoek laat daarnaast zien dat burgers de prestaties van een willekeurige organisatie negatiever evalueren als ze verteld is dat het een publieke instelling is dan als ze denken dat het een private organisaties is (Marvel, 2016), en doen dat bovendien

* $\quad$ S.C. Douglas, DPhil is universitair docent aan de Universiteit Utrecht.

Prof. dr. T. Steen is hoogleraar aan de KU Leuven.

Prof. dr. Z. van der Wal is hoofddocent aan de National University of Singapore en bijzonder hoogleraar aan de Universiteit Leiden. 
structureel wanneer ze beide sectoren ten opzichte van elkaar beoordelen (Van den Beukerom, Van der Voet, \& Christensen, 2019).

Deze onvrede is te begrijpen. De overheid functioneert niet perfect en de fouten van iconische, traditioneel gerespecteerde publieke instituties als de rechterlijke macht en het leger hebben een grote impact op de levens van mensen en hun percepties van publiek bestuur. Onderzoekscommissie na onderzoekscommissie rapporteert over gelijksoortige fouten en incompetenties (zie recent bijvoorbeeld de Commissie Giebels (2018) en de Commissie Fokkens (2019)) en de media doen daar gretig verslag van. Daarbij zijn sommige vormen van overheidsfalen, zoals budgetoverschrijdingen in IT-projecten (Goldfinch, Gauld en Baldwin, 2011), Kafkaëske bureaucratie (De Jong \& Rizvi, 2009) en de trage reactie op mondiale problemen als klimaatverandering aanhoudende kwesties die moeilijk goed te praten zijn. Ook verbinden sociologen het ongenoegen over de overheid aan het onderliggende gevoel van onbehagen en onzekerheid onder delen van de bevolking (Dekker et al., 2016).

Tegelijkertijd doet de overheid in de Lage Landen het gemiddeld genomen goed en internationaal gezien zelfs zeer goed. Zowel Nederland als België scoort op de ranglijstjes van OESO, Wereldbank, WHO en Transparency International in de wereldtop als het gaat om dienstverlening, levensgeluk, gezondheid, innovatie en integriteit (Van der Wal, 2017). Er is dus sprake van een zogeheten performanceperception gap. Als deze ranglijsten bovendien één ding aantonen in de lange nasleep van twee economische crises die Europa hard hebben getroffen, is het wel dat goed bestuur er ongelooflijk toe doet na decennia van een dominant bedrijfsmatig discours. Het is geen toeval dat econome Mariana Mazzucato over de hele wereld volle zalen trekt met haar pleidooi voor meer overheidsinvesteringen en haar visie op de cruciale rol van de publieke sector in maatschappelijke waardecreatie en het optimaal laten functioneren van markten (Mazzucato, 2015). Opiniemaker Rutger Bregmans en econoom Thomas Piketty gooien hoge ogen met het beargumenteren van meer overheidsinterventie en hogere belastingen om publieke belangen beter te waarborgen. De staat is volgens toonaangevende intellectuelen dus terug, maar wordt daarmee nog niet meer vertrouwd.

\section{Structurele kritiek vanuit bestuurskundigen, maar ook losse positieve noten}

Bestuurskundigen excelleren ondertussen ook in het aanwijzen van uitdagingen, complexiteit, ambiguiteit en het onderzoeken en benadrukken van problemen. Als discipline hebben we een uitgebreid repertoire opgebouwd om perverse effecten (Bevan \& Hood, 2006), beleidsfiasco's (Bovens \& 't Hart, 1998), 'red tape' (Van Loon et al., 2016) en andere problemen op te sporen. Het is uiteraard belangrijk dat deze kritische blik op de overheid bestaat. De staat is een machtig instituut en moet gecontroleerd worden. De genoemde problemen doen zich ook daadwerkelijk voor en moeten niet alleen geduid maar ook bestreden worden.

Tegelijkertijd moeten ook positieve praktijken en uitkomsten in het openbaar bestuur begrepen en gecommuniceerd worden. Binnen de bestuurskunde is gelukkig al veel aandacht voor positieve thema's als innovatie (De Vries, Bekkers en 
Tummers et al., 2016), 'performance' (Bouckaert \& Van Dooren, 2003), samenwerking (Ansell \& Gash, 2008), publieke waarde creatie (Moore, 2013), motivatie voor de publieke zaak (Worth et al., 2019), en de waarde van de klassieke bureaucratie (Du Gay, 2000. De vraag is echter in hoeverre al deze verschillende positieve inkijkjes optellen tot een samenhangend, overtuigend, aansprekend perspectief op overheidssucces.

Terugkerend discussiepunt is dan of deze positieve inkijken wel wetenschappelijk gefundeerd zijn of evenveel wetenschappelijke aandacht krijgen. Publieke waarde wordt bijvoorbeeld al dan niet terecht weggezet als een leuk maar niet onderzoekbaar perspectief (Hartley et al., 2017). Onderzoek dat de kritische kant van transparantie belichaamt, scoort hoger dan de meer positieve studies (Grimmelikhuijzen et al., 2013). Deze ongelijkheid kan deels verklaard worden door de breed gesignaleerde publicatie-bias voor heldere, kritische resultaten.

Deze kritiek wordt doorgetrokken in het verwijt dat onderzoek waarin 'good practices' centraal staan, vaak geen wetenschap maar verkapte consultancy is. Kritiek waarvan bijvoorbeeld de Harvard Business Review, toch een van de meest prestigieuze tijdschriften in de sociale wetenschappen om in te publiceren, geen last lijkt te hebben. Ons vakgebied kent zo'n tijdschrift met robuuste maar ook toegankelijke lessen uit geaggregeerd empirisch onderzoek eigenlijk niet. 'Business schools' en MBA-opleidingen mogen überhaupt graag succesverhalen, 'best practices' en 'benchmarks' delen. Onze bestuurskundestudenten leren we vooral hoe complex en ambigu het toch allemaal is.

\section{De noodzaak voor een robuust positief perspectief}

Het gat tussen overheidsfunctioneren en maatschappelijke waardering is veel beschreven en geanalyseerd, met een nadruk op het probleem van verkeerde verwachtingen. Misschien zit het in onze gemeenschappelijke klaagcultuur, in een toenemend gevoel van onbehagen veroorzaakt door een snel veranderende wereld, of in onze eigen versie van de ontwikkelingsparadox: des te beter we het hebben, des te beduchter we zijn op mogelijke misstappen of risico's (Boutellier, 2006).

Het uitgangspunt van dit themanummer is dat we niet alleen moeten kijken naar het bijstellen van de verwachtingen, maar ook naar het bijstellen van het beeld van de overheid. Wetenschappelijk gezien moeten we ons zelf de ambitie stellen om de verschillende positieve inzichten beter met elkaar te verbinden en te aggregeren. Maatschappelijk gezien moeten we voorkomen dat de leemte wordt opgevuld door doempredikers ('de democratische overheid is niet meer te redden') of door kwakzalvers ('door deze eenvoudige ingreep zijn we in één keer van het probleem af').

We zoeken een perspectief dat de dominante negatieve gevoelens in de maatschappij jegens de overheid kan nuanceren en volgens ons ook moet nuanceren omdat te negatieve sentimenten ten aanzien van de publieke sector onder burgers problematische gevolgen heeft. Als bestuurskundigen zijn we het aan onze stand 
verplicht een dergelijke, empirische en robuuste, nuance te produceren en te communiceren.

Het is niet voldoende om meer juichprofessoren in de media te laten verschijnen of nog maar een keer uit te leggen dat de overheid niet leuk maar toch belangrijk is ('het levertraan-argument'). We moeten ons bestaande kritische instrumentarium koesteren en uitbouwen, maar tegelijkertijd een krachtig en robuust perspectief ontwikkelen op de positieve kwaliteiten van het bestuur.

\section{De contouren van een robuust positief perspectief}

Het doel van dit themanummer is om de contouren van wat wij 'robuuste positiviteit' noemen te schetsen en enkele voorbeelden te geven van wetenschappelijk werk vanuit dat perspectief. 'Positieve bestuurskunde' stelt onderzoek naar wat de overheid goed doet en waar ze goed in is centraal. Dit perspectief dient degelijk wetenschappelijk te zijn, waarop vakgenoten kunnen voortbouwen en aansprekende inzichten genereert waar de praktijk mee vooruit kan.

We kunnen hierbij voortbouwen op enkele verwante initiatieven van onderzoekers in binnen- en buitenland. Paul 't Hart bemachtigde een grote ERC-beurs voor zijn Utrechtse onderzoek naar succesvol bestuur. Vanuit Utrecht werken Paul 't Hart en Scott Douglas ook met een groep van internationale, toonaangevende bestuurskundigen aan een internationaal manifest voor Positive Public Administration, al stuit deze inzet ook op veel weerstand van andere onderzoekers.

Onze inzet hier is ambitieus en wellicht zelfs idealistisch. Positieve bestuurskunde vraagt niet alleen om epistemologische en methodologische vernieuwing, maar ook om een herpositionering van bestuurskundigen in de samenleving. Het doel is een bestuurskunde die een breder en rijker verhaal kan vertellen over de meerwaarde van de overheid, naast de bestaande inzichten in misstappen. We doen hier onze voorzet voor vijf contouren van een robuust perspectief, gevolgd door een overzicht van de wijze waarop de artikelen in dit themanummer hieraan invulling geven.

\section{Integraal perspectief}

Het succes van de overheid kan niet gereduceerd worden tot een enkele indicator of dimensie. Robuust positief onderzoek zoekt naar voorbeelden of momenten waar het lukt om verschillende dimensies van succes samen te brengen. Marsh en McConnell (2010) definiëren volledig beleidssucces bijvoorbeeld als de optelsom van programmatisch succes (behalen doelen), procesmatig succes (totstandkoming verloopt soepel) en politiek succes (het beleid scoort goed bij kiezers en volksvertegenwoordigers). Er bestaan in potentie spanningen tussen deze verschillende dimensies en het is verleidelijk om vooral deze frictie te onderzoeken en uit te vergroten. Vanuit een robuust positief perspectief is het echter vooral relevant om te zoeken naar beleidshervormingen, publieke organisaties of maatschappe- 
lijke initiatieven waarin deze verschillende dimensies wel samenkomen. Hoe hebben ze dit voor elkaar gekregen?

\section{Context-gebonden perspectief}

New Public Management (NPM) excelleert in het vergelijkbaar maken van overheidsactiviteiten door middel van benchmarks en standaardindicatoren. Een robuuste positieve blik onderzoekt overheidssuccessen echter binnen de unieke mogelijkheden en moeilijkheden van de specifieke context waarin het overheidsoptreden tot stand is gekomen. De invulling van waardevol bestuur ziet er voor de gezondheidszorg anders uit dan voor het openbaar vervoer. Voor Rotterdam anders dan voor Luik. En tot zekere hoogte zelfs voor de ene burger anders dan voor de volgende burger. Deze focus op de specifieke context waarin overheidsoptreden tot stand komt, sluit aan bij de huidige beleidsmatige voorkeur voor decentralisatie, flexibiliteit en maatwerk. Een robuust perspectief zoekt niet naar het generieke succesmodel waaraan alle andere overheden moeten voldoen, maar naar de specifieke, context- en tijdgebonden vorm waarin succes zich voordeed.

\section{Intersubjectief perspectief}

Oordelen van succes en falen worden actief gevormd door verschillende actoren (bestuurders, ambtenaren, evaluatoren, burgers, media, etc.) en deze verhalen veranderen door de tijd heen. Een robuust positief perspectief is niet gefixeerd op 'objectieve' prestatiecijfers, om vervolgens te stranden in frustratie over het feit dat burgers die cijfers niet begrijpen, maar begint juist bij de waarderingen vanuit verschillende actoren. Waarderingen en opinies zijn hierbij niet zozeer interessant als datapunt ('gemiddeld genomen is iedereen tevreden'), maar als perspectief op de overheid om te doorgronden en te contrasteren ('vanuit dit perspectief vindt die actor dat'). Daarbij is het relevant om te zien hoe deze waarderingen tot stand komen in een proces van voortdurende beïnvloeding tussen burgers, media en politiek, tussen cijfers, verhalen, expertoordelen en eigen ervaringen. Een robuust positief perspectief wijst niet alleen maar een gevierde organisatie aan, maar legt ook bloot hoe het verhaal over die organisaties tot stand is gekomen en veranderd.

\section{Lerend perspectief}

Een robuust positief perspectief maakt leren mogelijk. We verwachten geen 'standaardrecepten voor succes' aan te treffen, daarvoor zijn er te veel verschillen tussen contexten. Het versterken van het leren richt zich op het beter worden in het geïnspireerd worden door anderen (het voorkomen van het 'Not Invented Here Syndrome') en tegelijkertijd beter worden in het distilleren van relevante lessen. Ook richt een positief perspectief zich op de leer- en feedbacksystemen die organisaties zelf hanteren. In een evaluatie van de Australische overheid stellen Luetjens en 't Hart (2019) bijvoorbeeld dat de uitdaging is om systemen voor het detecteren en leren van successen in te richten die even krachtig zijn als de bestaande systemen voor het detecteren en leren van fouten. 


\section{Wetenschappelijk perspectief}

Uiteindelijk moet een robuust positief perspectief ook vooral tot degelijke wetenschap leiden. Het perspectief moet aannames expliciteren, streven naar testbare en falsificeerbare theorieën, en transparant in de dataverzameling en onafhankelijk zijn. Dit vraagt om het niet enkel verzamelen van succesverhalen; statistische analyses en casusvergelijkingen vereisen juist een diversiteit van uitkomsten om tot robuuste uitspraken te kunnen komen. Een positieve bestuurskunde moet een onafhankelijke positie weten te behouden ten opzichte van politici en ambtenaren die maar al te graag succesverhalen willen horen.

\section{Bijdragen van dit themanummer: leren kijken naar successen}

De vier inhoudelijke artikelen in dit themanummer vormen elk een eerste invulling van dit robuuste, positieve perspectief op de overheid. Ze maken ook meteen duidelijk dat positieve bestuurskunde een brede kerk zal moeten zijn, waarin verschillende stemmen en denkkaders een plaats krijgen.

Het artikel van Overmans, Noordegraaf en De Rynck kijkt naar de beelden van succes die door de publieke sector zelf worden uitgedragen, middels een analyse van de juryrapporten van de belangrijkste prijzen voor overheidsorganisaties in België en Nederland. Door scherp te kijken naar de taal en motivatie die de jury's gebruiken voor het toekennen van de prijzen worden de verschillende beelden die leven over succes geëxpliciteerd en gecontrasteerd. De auteurs laten bijvoorbeeld zien dat de Nederlandse prijzen sterk gericht zijn op eenmalige prestaties die passen bij modieuze managementideeën en dat de Vlaamse prijzen zich meer richten op geconsolideerde resultaten van langdurige trajecten. In beide landen spelen wetenschap en meer verfijnde thema's uit de bestuurskunde een geringe rol.

Het artikel van Douglas en 't Hart verkent hoe we met behulp van het publieke waardeperspectief zicht kunnen krijgen op de kwaliteit van lokaal bestuur. Het publieke waardeperspectief gaat uit van de oordelen van betrokken actoren, maar uit onderzoek weten we echter dat stakeholders vaak verschillend en inherent negatief naar de overheid kijken. Het artikel laat enerzijds zien dat deze spanningen spelen - in het onderzoek worden gemeenten die bijvoorbeeld internationaal koploper zijn op woonbeleid door lokale actoren slechts beloond met een zuinig zeventje - maar anderzijds ook hoe achter deze sobere oordelen constructieve ambities schuilgaan.

Het artikel van Keulen en Kroeze laat zien hoe parlementaire debatten niet enkel waarde hebben als afrekenmoment, maar ook als moment van catharsis voor de samenleving. Het artikel laat zien hoe schijnbaar oeverloos praten in het parlement een toegevoegde waarde van publieke instellingen is. Het artikel biedt ook nog eens een vernieuwende methodologie voor het grijpbaar maken van catharsis als extra dimensie van waardevol bestuur. 
Het artikel door Van der Knaap en Turksema laat ten slotte zien hoe evaluatie vaker benut zal worden als ze positief wordt ingestoken. Op basis van verschillende voorbeelden, van de evaluatie van de zorg voor mensen met licht verstandelijke handicaps tot de evaluatie van het Natuurpact, laten de auteurs zien hoe een constructieve evaluatie-insteek goed samengaat met methodologische kwaliteit.

\section{Een goed gesprek over een positief perspectief}

Hopelijk leidt deze eerste opzet van een robuust positief perspectief tot navolging. Maar we willen niet dat positieve bestuurskunde leidt tot een kritiekloos halleluja-geluid vanuit de bestuurskunde. Zoals eerder benadrukt zien we het positieve perspectief als aanvullend op het even belangrijke kritische perspectief op de overheid. We hebben daarom Willem Trommel gevraagd dit themanummer af te sluiten met enkele kritische kanttekeningen. Hij stelt dat de positieve en kritische perspectieven op de overheid elkaar kunnen en moeten voeden, maar dat de bestuurskunde een nog radicalere agenda mag formuleren dan die in dit themanummer.

Verder hopen we dat 'positieve bestuurskunde' niet een aparte stroming wordt binnen de bestuurskunde. We hebben ons al voldoende onderverdeeld in subthema's en hyperspecialisaties, positieve bestuurskunde wil juist verschillende inzichten verbinden. We hebben daarom Geert Bouckaert gevraagd te verkennen hoe een positieve bestuurskunde ingepast kan worden in de bredere Europese onderzoeksagenda. Hij schetst de bredere Europese onderzoeksagenda voor de bestuurskunde en hoe positieve bestuurskunde binnen deze ontwikkeling past.

We hopen dat dit themanummer leidt tot vele enthousiaste, scherpe en hopelijk ook leuke gesprekken over wat de bestuurskunde moet en kan bieden. Bovenal hopen we dat deze gesprekken leiden tot vernieuwende, scherpe en interessante onderzoeksactiviteiten. We zijn overtuigd dat het invullen van een robuust positief perspectief op de overheid leidt tot meer verbonden theoretische inzichten, meer intrigerend empirisch materiaal en verdere praktische relevantie.

\section{Literatuur}

Ansell, C., \& Gash, A. (2008). Collaborative governance in theory and practice. Journal of Public Administration Research and Theory, 18(4), 543-571.

Beukerom, P. van den, Voet, J. van der, \& Christensen, J. (2019). Prestatiepercepties van burgers over publieke en private dienstverlening. Den Haag: Instituut Bestuurskunde.

Bevan, G., \& Hood, C. (2006). What's measured is what matters: Targets and gaming in the English public health care system. Public Administration, 84(3), 517-538.

Bouckaert, G., \& Dooren, W. van. (2003). Performance measurement and management in public sector organizations. In T. Bovaird \& E. Löffler (Eds.), Public management and governance (pp. 127-136). London: Routledge. 
Boutellier, H. (2006, november). De veiligheidsutopie: Over vitaliteit, bescherming en burgerschap. In D. Kouijzer \& A. van Gelder (red.) (Institut Néerlandais, Parijs), ErasmusDescartes Conferentie veiligheid en vrijheid (Vol. 24, pp. 131-143).

Bovens, M., \& Hart, P. 't. (1998). Understanding policy fiascoes. New Brunswick: Transaction Publishers.

Dekker, P., Ridder, J. den, Houwelingen, P. van, \& Kooiker, S. (2016). Zorg en onbehagen in de bevolking. Den Haag: Sociaal Cultureel Planbureau.

Du Gay, P. (2000). In praise of bureaucracy: Weber-organization-ethics. London: Sage.

Goldfinch, S., Gauld, R., \& Baldwin, N. (2011). Information and communications technology use, e-government, pain and stress amongst public servants. New Technology, Work and Employment, 26(1), 39-53.

Grimmelikhuijsen, S., Porumbescu, G., Hong, B., \& Im, T. (2013). The effect of transparency on trust in government: A cross-national comparative experiment. Public Administration Review, 73(4), 575-586.

Hartley, J., Alford, J., Knies, E., \& Douglas, S. (2017). Towards an empirical research agenda for public value theory. Public Management Review, 19(5), 670-685.

Jong, J. de, \& Rizvi, G. (Eds.). (2009). The state of access: Success and failure of democracies to create equal opportunities. Washington, DC: Brookings Institution Press.

Loon, N.M. van, Leisink, P.L.M., Knies, E., \& Brewer, G.A. (2016). Red tape: Developing and validating a new job-centered measure. Public Administration Review, 76(4), 662-673.

Luetjens, J., \& Hart, P. 't. (2019). Governing by looking: Learning from successes and failures. Melbourne: ANZSOG.

Marsh, D., \& McConnell, A. (2010). Towards a framework for establishing policy success. Public Administration, 88(2), 564-583.

Marvel, J.D. (2016). Unconscious bias in citizens' evaluations of public sector performance. Journal of Public Administration Research and Theory, 26, 143-158.

Mazzucato, M. (2015). The entrepreneurial state: Debunking public vs. private sector myths (Vol. 1). Anthem Press.

Moore, M.H. (2013). Recognizing public value. Cambridge: Harvard University Press.

Vries, H. de, Bekkers, V., \& Tummers, L. (2016). Innovation in the public sector: A systematic review and future research agenda. Public Administration, 94(1), 146-166.

Wal, Z. van der. (2016, 30 september). Zó slecht doen ambtenaren het ook weer niet. Het Financieele Dagblad, p. 11. Verkregen van https://fd.nl/opinie/1169487/zo-slechtdoen-ambtenaren-het-ook-weer-niet

Wal, Z. van der. (2017). Small countries, big performers: In search of shared strategic public sector HRM strategies in successful small countries. International Journal of Public Administration, 40(5), 443-458.

Worth, M., Pandey, S., Pandey, S.K., \& Qaddumi, S. (2019, July). Understanding Motives of Mega-gift Donors: A Study of the Higher Education Sector. In Academy of Management Proceedings (Vol. 2019, No. 1, p. 13815). Briarcliff Manor, NY 10510: Academy of Management. 